http://jmscr.igmpublication.org/home/ ISSN (e)-2347-176x ISSN (p) 2455-0450

crossref DOI: https://dx.doi.org/10.18535/jmscr/v8i1.169

Journal Of Medical Science And Clinical Research

\title{
Bilateral Synchronous ureteric Transional Cell Carcinoma presenting with oliguria - A Case Report
}

Authors

\author{
Maria Amanda L. Cardoso*, Pankaj D. Chari, Veku A. Gaude, Rajesh G. Halarnakar, \\ Prashant T.N. Mandrekar, Prashant R. Lawande, Nilesh B. Talwadker, \\ Madhumohan R. Prabhudessai \\ Department of Urology, Goa Medical College, Goa-India \\ *Corresponding Author \\ Maria Amanda L Cardosos
}

\begin{abstract}
Upper tract urothelial carcinomas account for 5\% of urothelial tumors. Urothelialtumors of pelvis are more common than that of the ureter, of which $24 \%$ occur in mid ureter. Bilateral synchronous Upper Tract TCC (transitional cell carcinoma) is rare with few reports in literature. This is a case report of a 43 year old male who presented with oliguria \& abdominal pain for 3 days. On examination patients vitals were stable. Abdominal examination was unremarkable and bladder was not palpable. On investigation Ultrasound showed bilateral Hydronephrosis with hydro ureter till mid ureter, distal ureters obscured, and bladder was normal. Plain CT abdomen confirmed ultrasound findings. No was calculus seen. Blood investigations revealed a raised Sr.creatinine of $9.5 \mathrm{mg} / \mathrm{dl}$. With a provisional diagnosis of retroperitoneal fibrosis, patient was taken up for Bilateral RGP \& DJ stenting. RGP revealed Bilateral mid Ureteric stricture, stenting was not possible and procedure abandoned. Patient was planned for left sided exploration. OT finding revealed left Pyelonephritic kidney, upper ureteric mass with dilation of ureter till mid ureter (Stricture site).Patient underwent Segmental ureterectomy with uretero-ureterostomy with DJ stenting. Histopathological examination revealed High grade solid urothetial carcinoma of ureter. Standard management of UTTCC is nephroureterectomy with cuff of bladder; however endoscopic management is being considered a good option in select patients.

Keywords: Bilateral, synchronous, ureteric, transitional cell carcinoma.
\end{abstract}

\section{Introduction}

Five percent of urothelial tumors arise from the ureter or the renal pelvisor calices, accounting for approximately $10 \%$ of upper tract neoplasms ${ }^{(1,2)}$. $25 \%$ of upper tract tumors occur in theureter, where $60 \%-75 \%$ of cases are found in thelower third, with no side predominance ${ }^{(2)}$. Bilateral synchronous Upper Tract TCC is rare with few reports in literature. Upper tract TCC typically occurs in the 6th and7th decades of life, with males affected three times more often than females ${ }^{(3)}$.

\section{Case Report}

This is a case report of a 43 year old male patient who presented with oliguria \& abdominal pain for 3 days, to the casualty. He had no history of haematuria, or any other significant history. On 
examination, patient was conscious, Bp $120 / 80 \mathrm{mmHg}$ pulse $86 / \mathrm{min}$ respiratory rate 16/min. Abdominal examination was unremarkable, bladder not palpable. Ultrasound abdomen pelvis revealed $\mathrm{B} / \mathrm{L}$ Hydronephrosis with hydroureter till the mid ureter, distalureter was obscured. Bladder was normal. A plain CT KUB done confirmed the ultrasound findings. There was no evidence of any ureteric calculus. (Fig 1)

Laboratory investigations were done as shown in (table 1) which revealed a rise in serum creatinine and microscopic haematuria.

With a provisional diagnosis of retroperitoneal fibrosis, patient was taken up for Bilateral RGP \& DJ stenting.RGP revealed bilateral ureteric stricture (fig 2), stenting was not possible and the procedure was abandoned. Subsequently bilateral Per cutaneous nephrostomies were passed and the serumcreatinine dropped to $3.5 \mathrm{mg} / \mathrm{dl}$. The patient then underwent a EC scan which revealed (L) Kidney: $82 \%$ function ERPF $109.1 \mathrm{ml} / \mathrm{min}$ and (R) Kidney: $18 \%$ function, ERPF $24.7 \mathrm{ml} / \mathrm{min}$.

In view of a better functioning left kidney patient was taken up for left side exploration. OT findings revealed Left pyelonephritic kidney with dilatation of ureter till mid ureter (site ofstricture) (fig 3) patient subsequently underwent Segmental ureterectomy with uretero-ureterostomy with DJ stenting.

Histopathological examination showed High gradesolidurothetial carcinoma of ureter. Subsequently patient underwent a B/L Nephrouretrectomy (fig 4).

Table 1 Laboratory Investigations

\begin{tabular}{|l|c|}
\hline Investigation & Results \\
\hline Haemoglobin & $10.4 \mathrm{gm} \%$ \\
\hline Total count & 14,000 \\
\hline Platelet count & $1.2 \mathrm{lac}$ \\
\hline Beeding\&clotting time & normal \\
\hline Srcreatinine & $9.5 \mathrm{mg} / \mathrm{dl}$ \\
\hline Urine routine & Numerous RBC \\
\hline ABG & Metabolic acidossis \\
\hline
\end{tabular}

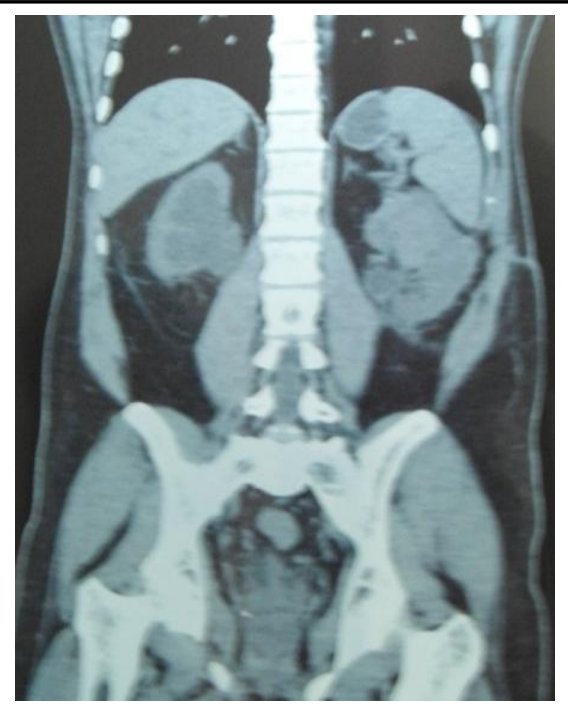

Figure 1: CT abdomen showing bilateral hydronephrosis with proximal hydroureter.

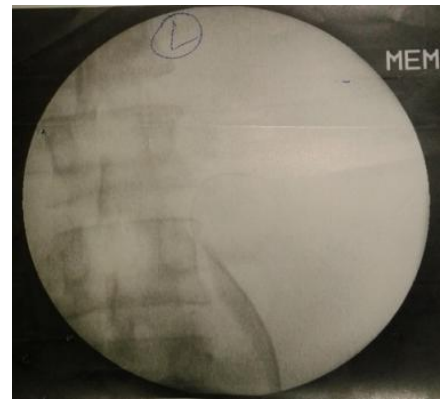

A



B
Figure 2 (A) \& (b) B/L Retrograde pyelogram : Left and Right stricture urethra respectively

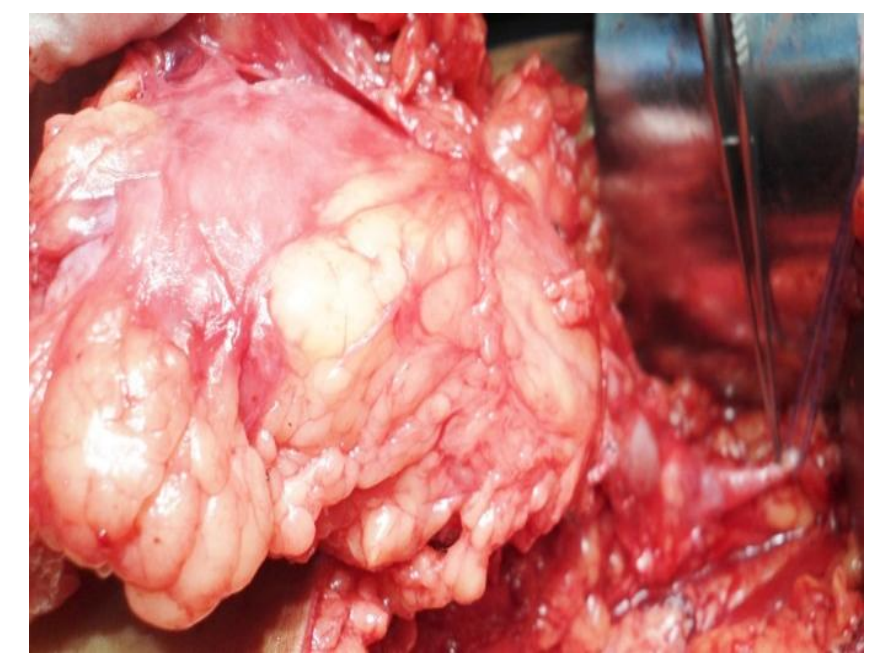

Figure 3: left Hydronephrotic Kidney with stricture site 




Figure 4: specimen with upper ureteric mass

\section{Discussion}

Transitional cell carcinoma (TCC) is commonly encountered in the urinary bladder and is usually diagnosed at cystoscopy. Five percent of urothelial tumors arise from the ureter or the renal pelvis or calices, accounting for approximately $10 \%$ of upper tract neoplasms ${ }^{(1,2)}$. Patients with TCC typically present with hematuria, which may be frank or microscopic. Upper tract TCC is common in families with "Balkan endemic nephropathy"(3). Most common risk factor is smoking with smokers being two to three times at a higher risk to develop TCC than nonsmokers. Other risk factors include Chemical carcinogens (aniline, benzidine, aromatic amine, azo dyes), and heavy caffeine consumption, these substances are metabolized and excreted in the urine as carcinogenicsubstances that act locally on the urothelium. Upper tract TCC is histologically and cytologically similar to bladder $\mathrm{TCC}^{(4)}$.

Pedunculatedor diffusely infiltrating tumor are less common,accounting for approximately $15 \%$ of upper tract TCCs, but tends to behave more aggressivelyand be more advanced at diagnosis ${ }^{(5)}$. CT urography is useful tool to aid in the diagnosis as it allows identification of lesions at an early stage. Nephroureterectomy and cuff of bladder excision is the standard treatment, in view of high recurrence rates and thin muscle coat in the upper tract. However Recent advances in endoscopic techniques have improved the efficacy of endoscopic management of the disease. ${ }^{(6)}$

\section{Conclusion}

Bilateral hydronephrosis with hydroureter secondary to Bilateral upper tract TCC presenting as oliguria must be considered as a rare presentation.

No grants

\section{Reference}

1. Hall MC, Womack S, Sagalowsky AI, Carmody T, Erickstad MD, Roehrborn CG. Prognostic factors, recurrence, and survival in transitional cell carcinoma of the upper urinary tract: a 30-year experience in 252 patients. Urology 1998;52:594-601.

2. Kirkali Z, Tuzel E. Transitional cell carcinoma of the ureter and renal pelvis. Crit Rev Oncol Hematol 2003;47:155169.

3. Chih-hsiung Kang, et al. Synchronous bilateral primary transitional cell carcinoma of the upper urinary tracts: Ten patients of more than five years of followup UROLOGY 63: 380i-380iii, 2004.

4. Melamed MR, Reuter VE. Pathology and staging of urothelial tumors of the kidney and ureter. Urol Clin North Am 1993;20:333-347.

5. Buckley JA, Urban BA, Soyer P, Scherrer A, Fishman EK. Transitional cell carcinoma of the renal pelvis: a retrospective look at CT staging with pathologic correlation. Radiology 1996; 201:194-198.

6. Chen GL, Bagley DH. Ureteroscopic management of upper tract transitional cell carcinoma in patients with normal contralateral kidneys. J Urol 2000;164: 1173-6. 